\title{
“MIS DOS PATRIAS": DE RUSIA AL PARAGUAY. LAS CARTAS DE RODOLFO RITTER A JUAN EMILIANO O'LEARY (1919 - 1929)
}

\section{"MY TWO COUNTRIES": FROM RUSSIA TO PARAGUAY. LETTERS FROM RODOLFO RITTER TO JUAN EMILIIANO O'LEARY (1919 - 1929)}

\section{Liliana M. Brezzo'}

Enviado: $27 / 07 / 2020$

Aceptado: $26 / 12 / 2020$

Resumen: El abogado y economista ruso Rodolfo Ritter (1864-1946) se afincó en el Paraguay en el año 1902 y, con excepción de una breve residencia en Posadas (Argentina), permaneció en el país hasta su fallecimiento. Amigo de los intelectuales más reputados de las primeras décadas del siglo veinte, interlocutor habitual de quienes componían el elenco dirigente del país fue, durante el gobierno de Eligio Ayala (1924-1928), asesor técnico en el Ministerio de Hacienda. Este estudio recupera la actuación de Ritter como experto y se posa en sus percepciones sobre las condiciones políticas y sociales del Paraguay a través del estudio del epistolario inédito con el historiador Juan E. O'Leary entre los años 1919 y 1929.

Palabras clave: Epistolarios; historia intelectual; intelectuales paraguayos; escritura de la historia. 
Abstract: The Russian lawyer and economist Rodolfo Ritter (1864-1946) settled in Paraguay in 1902 and, with the exception of a brief residence in Posadas (Argentina), he remained in the country until his death. A friend of the most reputable intellectuals of the first decades of the twentieth century, a regular interlocutor of those who made up the leading cast of the country was, during the government of Eligio Ayala (1924-1928) technical advisor in the Ministry of Finance. This study recovers Ritter's performance as an expert and focuses on his ideas about the political and social conditions of Paraguay through the study of unpublished letters with the historian Juan E. O'Leary between 1919 and 1929.

Keywords: Epistolary; intellectual History; Paraguayan Intellectuals; writing of History. 


\section{Introducción}

El abogado y economista ruso Rodolfo Ritter (1864-1946) se afincó en el Paraguay en el año 1902 y, con excepción de una breve residencia en Posadas (Argentina), permaneció en el país hasta su fallecimiento. Editor del semanario El Economista Paraguayo (1908-1923), amigo de los intelectuales más reputados de las primeras décadas del siglo veinte, interlocutor habitual de quienes componían el elenco dirigente del país fue, durante el gobierno de Eligio Ayala (1924-1928), asesor técnico en el Ministerio de Hacienda. Este artículo presenta la actuación de Ritter como experto del Estado paraguayo, así como algunas de sus percepciones sobre las condiciones políticas y sociales del Paraguay a través de lo que revela una parte del epistolario inédito con el historiador Juan Emiliano O'Leary. El repertorio documental está compuesto por 196 cartas de Ritter a O' Leary y 8 copias de cartas de O'Leary a Ritter, comprendidas entre los años 1919 y 1946. ${ }^{2}$ El mayor tráfico epistolar se produce entre los años 1925 y 1929 en los que el historiador reside en
Europa cumpliendo funciones diplomáticas. Un nuevo pico (aunque comparativamente menor al anterior) corresponde al bienio 1936-1937 en el que O'Leary permanece en Italia en calidad de Encargado de Negocios. Queda aún pendiente la posibilidad de recomponer ese diálogo a dos voces de la correspondencia, aunque de momento contamos con una mayor proporción de las piezas que Ritter envió a O'Leary.

La concentración de cartas que se da entre los años 1925 y 1929 (26 cartas en 1925, 47 cartas en 1926, 35 cartas en 1927, 29 cartas en 1928 y 11 cartas en 1929) componen, pues, un elenco epistolar de excepcional valor en el que aparecen ejes temáticos de diverso tipo y alcance: las labores de asesoramiento desenvueltas por Ritter en el gobierno de Eligio Ayala, la difusión y venta en el Paraguay de las obras históricas de O'Leary editadas en Europa, las relaciones de amistad con los actores políticos del momento, las visiones de Ritter y de O'Leary sobre el conflicto chaqueño.

\footnotetext{
2 Se trata de un recuento preliminar que deberá ser perfeccionado.
} 


\section{Las cartas y el mundo político e intelectual paraguayo}

A primera vista, parece que poco se puede decir de investigaciones sobre epistolarios centrados en el mundo político o intelectual paraguayo. Sin embargo, ya merecen ser reseñadas publicaciones recientes por el sólo hecho de poner a disposición, mediante ingentes esfuerzos de transcripción y de edición crítica, materiales relevantes, o por constituir el inicio de proyectos más ambiciosos para reconstruir la historia política e intelectual contemporánea. Quizás uno de las primeros trabajos en esa dirección, dado a conocer entre los años 2006 y 2007, haya sido la robusta correspondencia que sostuvieron el diplomático paraguayo Gregorio Benites (1834 - 1909) y el jurista argentino Juan Bautista Alberdi (1810 - 1884) durante la segunda mitad del siglo diecinueve, que ha permitido restituir las ideas y la participación de dos actores principales de las elites políticas dirigentes de sus respectivos países en los procesos de construcción nacional, así como los términos de la defensa intelectual y de la propaganda paraguaya en Europa que ambos desenvolvieron durante la guerra contra la Triple Alianza. ${ }^{3}$ Más recientemente, figuran investigaciones que se asientan en el archivo personal del historiador Juan E. O'Leary, uno de los más cuantiosos del siglo veinte; así, por ejemplo, contamos con la recuperación del intercambio epistolar que mantuvo con Gregorio Benites entre los años 1900 y 1909 y que proyecta, entre otros ejes temáticos, los afanes de los corresponsales para edificar en el Paraguay, a comienzos del siglo veinte, una "historia patriótica". ${ }^{4}$ Figuran también los trabajos de María Laura Reali, dedicados a dar a conocer el carteo que entre los años 1905 y 1953 mantuvieron O'Leary y el político e intelectual uruguayo Luis Alberto de Herrera, que han auscultado problemáticas particularmente relevantes. como la operación política/historiográfica en que

3 Juan Bautista Alberdi - Gregorio Benites. Epistolario inédito (18641883) (2006-2007) Asunción: Academia Paraguaya de la Historia - Fundación Biblioteca y Archivo de Jorge M. Furt - Universidad Nacional de General San Martín, 3 tomos.

4 Brezzo (2013). 
se empeñaron ambos corresponsales para la consolidación, en el ámbito platense, de la lectura revisionista de la Guerra del Paraguay, así como sus acciones de propaganda a favor de la causa paraguaya durante la Guerra del Chaco. ${ }^{5}$

Hay que mencionar también las investigaciones sobre la trayectoria intelectual de Juan Natalicio González que se posan en sus epistolarios. Andrea Tutté logra precisar algunos de los proyectos culturales que acometió Natalicio como la fundación de la Editorial de Indias que publicó en París, en los años veinte, un elenco notable de obras paraguayas, y el derrotero de Guarania que se constituyó en una de las revistas culturales más importantes del siglo veinte en América Latina. A su vez, como lo demuestra esta autora, el estudio de los epistolarios de González ha desplegado su conversación a distancia con una amplia galería de reconocidos intelectuales del continente como el colombiano Germán Arciniegas, el peruano Luis
Alberto Sánchez, los brasileños Gilberto Freyre, Newton Freitas y Lidia Besouchet, los argentinos Alfredo L. Palacios, Gabriel del Mazo, Luis Dellepiane, Atilio García Mellid y Raúl Scalabrini Ortiz. ${ }^{6}$ En el caso particular de la correspondencia con Germán Arciniegas, la investigación que dieron a conocer hace poco Marcela Quinteros y Carlos Davis Suárez Morales aporta elementos significativos para situar a ambos intelectuales en las luchas del antiperonismo latinoamericano. ${ }^{7}$ Cabe resaltar también aquí el estudio de Tomás Sansón Corbo sobre la correspondencia del político e historiador Carlos Pastore Olmedo con los historiadores "liberales" paraguayos de la segunda mitad del siglo veinte. ${ }^{8}$

Esta reciente historiografía abre nuevas perspectivas para una historia intelectual y política del Paraguay contemporáneo: posibilita rastrear, por ejemplo, "la evolución de la obra de los dialogantes, las metamorfosis en sus opiniones, el cambiante mapa de su universo de inter-

\footnotetext{
5 Véase, entre otras contribuciones, Reali (2012) y Brezzo - Reali (2017).

6 Tutté (2017) y Tutté (2019).

Quinteros - Suárez Morales (2016).

8 Sansón Corbo (2018)
} 
locución, la existencia de proyectos nunca concretamente realizados pero que no por ello dejaron de marcar con su huella el periplo de los autores". ${ }^{9}$ En un plano más íntimo, los estudios reseñados aquí facilitan analizar cuestiones de gran importancia a la hora de elaborar una contextualización completa de las ideas y de la obra intelectual de los corresponsales como su estado anímico, su situación familiar, sus prejuicios de clase, de género, de raza, sus creencias profundas en materia política y su percepción de su propia persona en relación a la mirada de los otros en los múltiples planos de la vida social. A su vez, como bien enumera Carlos Myers, este tipo de abordajes muestran las distintas funcio- nes de los intercambios epistolares, que pueden incluir el debate intelectual, es decir, la confrontación de puntos de vista opuestos o no necesariamente coincidentes, provocada muchas veces por uno de los dos interlocutores; la definición del propio pensamiento o el uso del medio de la escritura con un destinatario específico para "pasar en limpio" una reflexión quizás no del todo clara en un primer momento; la justificación a posteriori de posiciones tomadas que habían alcanzado estado público y la proyección hacia la posteridad de la propia figura como intelectual, donde las cartas resultan no solo ser el vehículo vivo de un pensamiento en movimiento sino el registro permanente del mismo. ${ }^{10}$

\section{De Rusia al Paraguay}

Lucía Giovine Gramatchicoff subraya que fue "el primer ruso cuyo importante aporte quedó grabado en la historia paraguaya" para referenciar la temprana llegada al país de Rodolfo Ritter, algunos años antes del establecimiento de

las relaciones diplomáticas entre Rusia y el Paraguay, que se concretó en el año 1909 con la acreditación del conde Mauricio Prozar como primer Enviado Extraordinario y Ministro Plenipotenciario. ${ }^{11}$ 
Los orígenes familiares, así como las circunstancias que lo trajeron al Paraguay han sido reconstruidos en la biografía elaborada por Xavier de Assis Careaga, sobre la base de documentación proveniente del archivo de la familia Ritter y del estudio del semanario El Economista Paraguayo. Gracias a ese esfuerzo biográfico conocemos que Rodolfo Ritter nació en Moscú el 9 de julio de 1864 en el seno de una familia de la nobleza vinculada a las finanzas y a la industria. Su padre era el conde León Ritter y su madre, de origen inglés, la condesa Regina Layton. Realizó estudios superiores en la Universidad de Moscú, donde se doctoró en Derecho y Ciencias Sociales, en Economía y obtuvo una licenciatura en Ciencias Físico Matemáticas. Con posterioridad, continuó su formación en La Sorbona, en Paris. Y, como corolario del período universitario realizó el grand tour, una serie de viajes por el continente europeo, Estados Unidos y Asia, requisito indispensable de "todo aristócrata ruso". El alto valor que, en adelante, Ritter asignó a la experiencia del viaje parece haber tenido su origen en ese recorrido iniciático. Así consta, por ejemplo, en El Economista Paraguayo cuando se refiere a algunos de sus frutos: "Casi todo viaje por un país desconocido o poco conocido dilata el alma, ensancha el horizonte espiritual, aumenta el caudal de conocimiento, vigoriza los sentidos y su impresionabilidad. En una palabra, constituye un enriquecimiento más o menos grande de la personalidad. Por eso los viajes por tierras nuevas son tan amados por nuestra civilización moderna. No en vano se dijo que viajar es renovarse". ${ }^{12}$

Las circunstancias que rodearon a la llegada de Ritter al Paraguay conectan con su oposición intelectual al régimen zarista de Nicolás II Romanov. Sus críticas y cuestionamientos diseminados en la prensa rusa hicieron que su situación se volviese insostenible y que fuera obligado a abandonar el país. ${ }^{13}$

el Paraguay a inicios del siglo veinte pueden verse Gramatchicoff (2009). Nakayama (2017), Alexandróva (2017).

12 El Economista Paraguayo, Asunción, sábado 10 de mayo de 1919. Citado por Careaga (2007), página 20.

13 Carega (2007), pp. 23-24. 
Durante los primeros años en el Paraguay, Ritter se dedicó a la producción ganadera en una estancia que adquirió en Arroyos y Esteros, que había pertenecido a Benigno Ferreira. Entre los años 1904 y 1905 integró la Junta Económica Administrativa de esa localidad. En lo personal, desde 1910 fue su compañera Apolonia Sosa (1891 -1962) con quien contrajo matrimonio en 1929.

Sus preocupaciones intelectuales hallaron cauce tempranamente a través de colaboraciones en la Revue Commerciale: finances, commerce, industrie, agriculture, inmigration, que se publicaba íntegramente en francés en Asunción. El historiador Alfredo Seiferheld ratifica que en ella hizo Ritter sus primeras armas literarias, destacando su singular "apego" hacia todo lo hebreo. ${ }^{14}$ En 1906 publicó varios artícuIos en la Revista del Instituto Paraguayo y en Amigos de la Educación ${ }^{15} y$, al año siguiente, sobre la base de un ciclo de conferencias que dictó en el Instituto Paraguayo publicó un opúsculo titulado La cuestión monetaria en el Paraguay.

En 1908 se instaló de manera permanente en Asunción, en una casa situada en la calle Alberdi entre Haedo y Humaitá y el 12 de setiembre inició la publicación del periódico semanal El Economista Paraguayo para difundir, según explicaba en el prospecto, "sanas ideas económicas en el orden monetario y cambiario". ${ }^{16}$ La cartografía de sus interlocutores intelectuales durante esos años nos devuelve un territorio poblado por el escritor español Rafael Barret - con quien mantuvo una polémica intensa acerca de la existencia o no de la cuestión social en Paraguay - , por el naturalista suizo Moisés Bertoni - cuyo carteo y referencias a las obras de Bertoni en El Economista Paraguayo dan cuenta del respeto intelectual que se profesaban-, así como por los intelectuales paraguayos Ricardo Brugada, Fulgencio Moreno, Enrique Solano López, Eligio Ayala, Eusebio Ayala, Juan Natalicio González, Pablo Max Ynsfrán, Manuel Domínguez,

\footnotetext{
14 Seiferheld (1984), p.90

15 Careaga (2007), página 32.

16 Ibidem, p. 29.
} 
Justo Pastor Benítez, Juan E. O'Leary. En 1923, ante dificultades para continuar con su impresión, debió cesar la publicación, un momento que constituyó, junto a la venta de su establecimiento ganadero en Arroyos y Esteros, un parteaguas en su vida profesional. En adelante, su cercanía con el elenco dirigente que componía el gobierno de Eligio Ayala lo conduciría a desplegar distintas labores como experto.

\section{El epistolario Ritter - O'Leary}

La expresión castellana "De puño y letra" hace referencia a un documento que está escrito por la misma persona que lo firma. El modismo aplica a las cartas de Ritter dirigidas a O'Leary, redactadas por su propia mano con una destreza casi perfecta en el uso de la gramática española. Entre 1919 (fecha de la primera carta de Ritter que se conserva) y el año 1925, las piezas epistolares dirigidas a O'Leary son exiguas (1 carta de 1919, 1 de 1920, 2 cartas del año 1922, 2 cartas de 1924) y tienen como lugar de remitente la Estancia Yacabi, en Arroyos y Esteros, o bien Asunción durante los meses de verano cuando O'Leary y su familia residen en Caacupé. La conversación a distancia se hace robusta desde mediados de 1925 cuando el historiador se instala en Madrid como Encargado de Negocios del Paraguay.
El ritmo quincenal de las cartas -en algunos tramos semanal- lo convierten a Ritter en su principal corresponsal en el Paraguay, que le informa sobre la vida política e intelectual con nombres y apellidos: referencias y comentarios sobre "Beli", “Eligio", "Justo P.", "Ynsfrán" dan cuenta de la soltura y la cercanía con las que se mueve en las altas esferas del gobierno.

Aunque de momento no hemos podido fijar con precisión su inicio, la primera carta de Rodolfo Ritter revela una amistad de larga data; pruebas de esto es el encabezado "Mi querido O'Leary!", así como la constante irrupción en el relato epistolar de temas de la vida privada, como las vicisitudes familiares en Arroyos y Esteros, la textualización de sentimientos ante el fallecimiento de "Ricardito" Brugada, el agobio de Ritter por 
el bajo rendimiento escolar de su hijo. ${ }^{17}$ Las primeras misivas llevan el membrete institucional de El Economista Paraguayo, cuyo contenido se ve atravesado, precisamente, por extensas descripciones sobre las dificultades para continuar con la edición de la revista, circunstancia que lo llena de cavilaciones sobre posibles aplicaciones prácticas de sus conocimientos y capacidades en el campo de la teoría económica a las que caracteriza como "ciertamente raros en este continente". Por lo pronto, en una de las dos cartas del año 1924 le anticipa a O'Leary que iniciará gestiones para integrar el elenco de colaboradores del diario La Prensa, de Buenos Aires, en el que trabaja Fulgencio Moreno, mediante el envío de una serie de artículos titulados "Unas tendencias de la organización económica del presente"; entretanto, se hace columnista asiduo de los diarios asuncenos El Liberal y La Nación. ${ }^{18}$
La otra carta de 1924, fechada en el mes de diciembre, tiene un especial contenido. En ella describe Ritter el último viaje desde Asunción a Arroyos y Esteros, cuya "hermosura del paisaje, que no me cansa después de 22 años, es el encanto de nuestra existencia", poco antes de la venta de su establecimiento. Se detiene en describir lo que percibe como las miserias de la campaña, las dificultades para continuar con su establecimiento y despliega su visión acerca de lo que define como el "drama íntimo del Paraguay", es decir, las razones de las carencias, de la "pobreza crónica, de la falta de todos los elementos de una vida desahogada, en medio de esta tierra tan pródiga". Para Ritter es palpable, luego de tantos años de residencia, el "atraso patético, si se compara la campaña con Asunción y otros centros de población. Atraso que se mide por siglos... ¡Qué magnífica tierra, que mina inagotable para un gran escri-

17 Biblioteca Nacional de Paraguay, Colección Juan E. O'Leary (en adelante BNP-CJO), De Rodolfo Ritter a Juan O'Leary, Asunción, 18 de diciembre de 1919 y 20 de febrero de 1920. Existe, como antecedente de los vínculos entre las dos familias, una carta de Apolonia de Ritter a Dorila de O'Leary fechada en Estancia Yacabi (Arroyos y Esteros), el 21 de abril de 1916.

18 Ibidem. De Rodolfo Ritter a Juan E. O'Leary, Asunción, 5 de agosto de 1924. 
tor nacional, evocar el drama íntimo del Paraguay: la antítesis entre esos dos mundos: el de la ciudad y el de la campaña! En todas partes existe esa antítesis, pero en ninguna parte la sentí tan fuerte como en Rusia y en el Paraguay: mis dos patrias. Y como en Rusia los más grandes escritores, -Tolstoi, Turguenieff, Dostoievski, Korolenko, Nikrasoff y centenares de otros menores- no se cansaban en pintar esa antítesis, asimismo en el Paraguay aparecerán escritores que den expresión artística a ese drama íntimo". 19 Resulta poco habitual este tipo de reflexiones en el elenco epistolar que hemos examinado, quizás porque Ritter utilizaba el Semanario como lugar para exponer sus percepciones sobre la vida económica y social. Lo peculiar en esta carta, dirigida en la esfera privada, es que sus ideas se despojan de términos técnicos y se revisten de la sensibilidad de un agudo confi- dente que lleva viviendo en el Paraguay más de veinte años. ${ }^{20}$

Como hemos apuntado, el exiguo tráfico epistolar se intensifica con la partida de O'Leary a Europa, en julio de 1925. El 21 de ese mes, tan solo una semana después de que el historiador dejara el Paraguay, Ritter le comunica, con inocultable alegría, que Adolfo Aponte, ministro de Justicia, Culto e Instrucción Pública, le ha ofrecido la cátedra de Economía Política en la carrera de Derecho en reemplazo de Justo Pastor Benítez, que ha sido designado Cónsul General en Roma. ${ }^{21} \mathrm{La}$ propuesta, escribe, cuenta con el asentimiento "de Eligio", el presidente del Paraguay y de "Belisario", el ministro de Interior. Siguiendo el relato epistolar, cuando se le comunicó a este último el propósito de su nombramiento habría exclamado: "Al fin hacéis lo que hace años debía haberse hecho". ${ }^{22}$

19 Ibidem. De Rodolfo Ritter a Juan E. O'Leary, Estancia Yacabi, Arroyos y Esteros, 29 de diciembre de 1924.

20 Por lo demás, la descripción de Ritter se ajusta completamente a la realidad social. En el campo, el principal problema era la distribución de la tierra; se estima que, en esos años, al menos el 70\% de los agricultores ocupaban o trabajaban predios ajenos. Véase Scavone Yegros (2010), pp. 231-262 y Lewis (2016), pp. 171-178.

21 BNP-CJO. De Rodolfo Ritter a Juan E. O'Leary. Asunción, 21 de julio de 1925.

22 Ibidem. 
La incorporación de Ritter al claustro universitario encaja en un proyecto de reforma general de la enseñanza en la Universidad Nacional de Asunción, que contempla la contratación de catedráticos extranjeros, el autogobierno y la autonomía. ${ }^{23}$ El movimiento reformista que se había iniciado en Córdoba (Argentina) se materializa en esos años en el Paraguay con el envío por parte del presidente Ayala al Congreso de un proyecto de ley que, explicaba Ritter, introduce "cierta autonomía universitaria: el claustro de catedráticos elige una terna, de entre la cual el Poder Ejecutivo nombra al rector por cuatro años. Los asuntos de la Universidad se dirigen por un Consejo de nueve miembros: a más del rectory de los decanos, tres profesores nombrados por el Poder Ejecutivo, tres electos por los estudiantes. Cada facultad se dirige por un Consejo, electo, así como el decano, por el cuerpo docente". ${ }^{24}$ La marcha de esta reforma constituye un tema recurrente en las cartas del segundo semestre de 1925; en particular, en cuanto a la carrera de Derecho informa Ritter a O'Leary que se restablecía el bachillerato único, con intensificación de las materias culturales como literatura, lógica, historia, y el latín obligatorio.

De este modo, los últimos meses del año encuentran a Ritter en los preparativos de su cátedra de Economía Política: “Estoy preparando mi curso de economía política. Tengo sobre la enseñanza universitaria otras ideas que las corrientes. Opino que el profesor tiene que ofrecer a los alumnos lo que no está en los manuales o lo que está expuesto de modo insuficiente. Así es que esa preparación me da bastante trabajo, el que adelanto despacio: tal vez a causa de los calores". ${ }^{25}$ Y el año se cierra con la siguiente resolución: "se fundará una cátedra libre de economía política, daré de 25 a 30 conferencias de carácter monográfico, según mi elección ¡Al fin!, estoy contento. Tendré un objeto concreto de vida..."26

\footnotetext{
23 Ibidem.

24 VV. AA, UNA. 120 años de historia, Asunción, 2009, pp. 27-28.

25 BNP-CJO. De Rodolfo Ritter a Juan E. O'Leary. Asunción, 21 de noviembre de 1925.

26 Ibidem. De Rodolfo Ritter a Juan E. O'Leary. Asunción, 19 de diciembre de 1925.
} 
En el plano de las amis- Viejo Continente le ha servido tades, el verano 1925-26 trae al intelectual paraguayo para a su círculo cercano a Juan calibrar "la superioridad de Natalicio González, recién lle- Europa" en cuanto a la cultura gado de Europa, sobre el que material y a la vida intelectual. Ritter no escatima elogios; Así describe la en la carta a entiende que el periplo por el O'Leary del 2 de enero de 1926:

Natalicio Ilegó. Le veo bastante a menudo y cada vez
le aprecio más. Jamás vi a un hispano-americano, que
haya aprovechado más su estadía en Europa. Ahora es
un hombre. Nada de niño. Un hombre serio, de juicios
serenos y maduros, sobre los más de los problemas.
Supo penetrar en la médula de los factores que cons-
tituyen la superioridad de Europa y el secreto de su
civilización. Irá lejos... así como tantas veces lo hemos
constatado; pues no solo [excede] en talento o inteligen-
cia, sino carácter. En esto está el secreto de sus éxitos
presentes y futuros. En todo caso su trato será suma-
mente provechoso para la juventud. Por suerte, piensa
quedar aquí 10 o 12 meses. Lo que me gusta tanto en
él es su amor a la patria: sin frases, sin declamaciones,
ni aberraciones, pero sí, vidente, activo, obrante. 27

La admiración hacia Natali- frecuento, tanto más le aprecio enlaza con la reconfiguración cio. Tiene un fondo que pocos de su círculo de amistades a sospechan. Es una verdadera consecuencia de la partida de esperanza para el Paraguay". ${ }^{28}$ O'Leary, con quien conversaba "a diario". Ahora intensifica el trato de amistad con Pablo Max Ynsfrán mediante visitas semanales a su casa en Areguá, y del que asegura, "cuanto más le tiva con soltura el trato con los Se cartea con constancia con el naturalista Moisés Bertoni, mantiene esporádicas pero extendidas conversaciones con el presidente Eligio Ayala. Y cul-

27 Ibidem. De Rodolfo Ritter a Juan E. O'Leary. Asunción, 2 de enero de 1926.

28 Ibidem. Véase también las cartas correspondientes al 9, 16, 23 y 30 de enero de 1926. 
ministros, diputados, senadores y hombres cercanos al gobierno en encuentros en el Unión Club, como Enrique Bordenave, Andrés Gubetich, Luis De Gásperi, Eliseo Da Rosa, entre otros. ${ }^{29}$

\section{Ritter en el gobierno de Eligio Ayala}

Desde el mes de enero de 1926 las cartas de Ritter tienen como hilo conductor sus labores de asesoramiento en el Ministerio de Hacienda que se acordaron "con un sueldo de 4000 pesos, con la promesa de mejora en el porvenir y la asignación de un despacho en Palacio". ${ }^{30}$ La designación estuvo precedida por una extensa entrevista con el presidente Eligio Ayala. Si bien el motivo inicial del encuentro es la gestión de Ritter, a instancias de O'Leary, para que el gobierno le otorgara al diplomático un sobresueldo, en la carta del 28 de noviembre de 1925 Ritter no sólo da cuenta del resultado en torno a ese tema, sino que se detiene en otros temas que conversó con "Eligio" por espacio de las "tres horas":

\section{Ayer, para hacer la última} tentativa en sus asuntos, fui a ver a Eligio, quien me recibió muy amistosamente y me retuvo a su lado durante casi tres horas. En su asunto obtuve el siguiente resultado: Eligio abandona el rígido ino! -non possumus- detrás del cual se atrincheró frente a De Gásperi, y me prometió que haría lo posible para ver la forma en que se podría hacer llegar a Ud. ese sobresueldo de \$ 100 oro, sobre los $\$ 500$ oro presupuestados, sin extender esa medida a los demás cónsules, especialmente a Galeano y J. Benítez que, según él, tienen iguales, si no mayores títulos, a esa consideración (iel partidismo!). Me aseguró que sinceramente deseaba complacerle y que haría 10 posible para lograrlo. ${ }^{31}$

\footnotetext{
29 Ibidem, Asunción, 22 de julio y 5 de agosto de 1925.

30 Ibidem, Asunción, 30 de enero de 1926.

31 Ibidem. De Rodolfo Ritter a Juan O'Leary, Asunción, 28 de noviembre de 1925. Hay que decir que el epistolario muestra que las relaciones intelectuales de Ritter y Ayala no fueron sencillas. Si bien existían coin-
} 
De hecho, el núcleo principal de la extensa carta plasma la preocupación principal de Ayala a finales de 1925: la cuestión militar vinculada al conflicto chaqueño, el desencadenamiento de las pasiones y los apetitos en torno de la futura presidencia; según Ritter el presidente le dijo textualmente:

"Ahora estamos en un paraíso, pero pronto entraremos en el infierno" $y$, agrega Ritter, "se quejó de las innúmeras dificultades que, a cada paso, oponía la "política" a toda obra creadora; de la inutilidad redomada de los ministros y jefes de reparticiones: "viejos y jóvenes". En síntesis, 10 halla a Ayala "muy pesimista". Y, en lo físico, "delgado, más pálido y desmejorado. Evidente- mente, para un hombre de alta conciencia, la presidencia en el Paraguay es un calvario". ${ }^{32}$

En momentos del encuentro con el presidente paraguayo Ritter daba los últimos toques a un informe sobre la situación monetaria del país - ampliación del opúsculo que diera a conocer en 1907 - sobre la base de un nuevo relevamiento de las publicaciones oficiales, como las de la Dirección de Tierras y Colonias, los Boletines Trimestrales de la Dirección de Estadística. Al dar cuenta a O'Leary de estos avances desliza una crítica de la situación política en el país en contraste con su constante actividad intelectual: "Aquí ninguna novedad. Calma chicha. En política, en los negocios, en la vida social, en la vida intelectual. Estamos en perpetuas vacaciones". 33

cidencias de fondo en cuanto al modelo de democracia liberal para el Paraguay, otras cuestiones hacen que Ritter se queje del carácter del presidente y de su áspero trato. Por ejemplo, en carta del 9 de enero de 1926 escribe Ritter: "Eligio está resentido por mi informe sobre el Bance Central y mi informe (secreto) sobre la situación monetaria del Paraguay".

32 Ibidem.

33 Ibidem. De Rodolfo Ritter a Juan E. O'Leary, Asunción, 31 de octubre de 1925 y 8 de diciembre de 1925. Durante los meses de verano 1925-26 Ritter trabajó en un informe sobre la situación monetaria del país, cuyos resultados eran los siguientes: "Hice un estudio concienzudo: resalta de modo inconcuso que aquella no es tan brillante como 
El trato personal con Eligio necesidad de "apretar la econoAyala se proyecta nuevamente mía", de profundizar de manera en la carta de Ritter a O'Leary del discreta y silenciosa la prepara30 de enero de 1926 en la que ción para la defensa del Chaco. describe la segunda conversa- En el extendido intercambio, ción con el primer mandatario siguiendo el testimonio de Riten la que le habría explicado la ter, Ayala rememoró también:

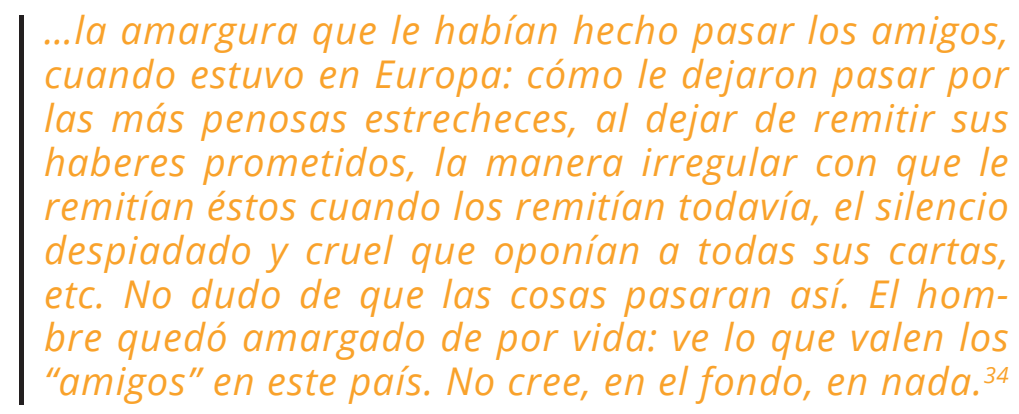

En febrero de 1926 Ritter

sobre la situación económica del concluye el informe sobre la situación monetaria, y lo anexa a una carta O'Leary. ${ }^{35} \mathrm{Al}$ mes siguiente inicia, a solicitud del Ministerio de Hacienda, la preparación de una memoria

Paraguay; los progresos del que califica un "engorroso trabajo" los presenta al ministro Benítez, que los describe como "muy interesantes". ${ }^{36} \mathrm{Su}$ condición de asesor técnico lo habilita a "ir a

aparece. Gracias a la estúpida e imperdonable inflación de \$ 86.000.000 c/l., hecha sin ton ni son, el peso paraguayo perdió de 40 a 50 por 100 de su fuerza adquisitiva. Así es que la estabilidad del cambio se obtuvo con la enorme desvalorización interna del peso paraguayo. ¡Qué adefesio, qué ironía! Y lo más doloroso es que todo eso se hubiera podido evitar con un poco de idoneidad efectiva".

34 Ibídem. De Rodolfo Ritter a Juan E. O'Leary. Asunción, 30 de enero de 1926.

35 Ibidem. De Rodolfo Ritter a Juan E. O'Leary, Asunción, 2 de febrero de 1926.

36 Ibidem. De Rodolfo Ritter a Juan E. O'Leary, Asunción, 6 de marzo de 1926. 
Palacio" todos los días, conversar con los ministros y con el puesto que se le delegan para presidente, averiguar e insistir en el "asunto del sobresueldo de O'Leary". Las cartas manifiestan que sus labores se consolidan con el correr de los meses su estudio y resolución nuevos asuntos, como la confección de una "historia de los empréstitos del Paraguay", un proyecto para cuya ejecución acude a su corresponsal en Europa:

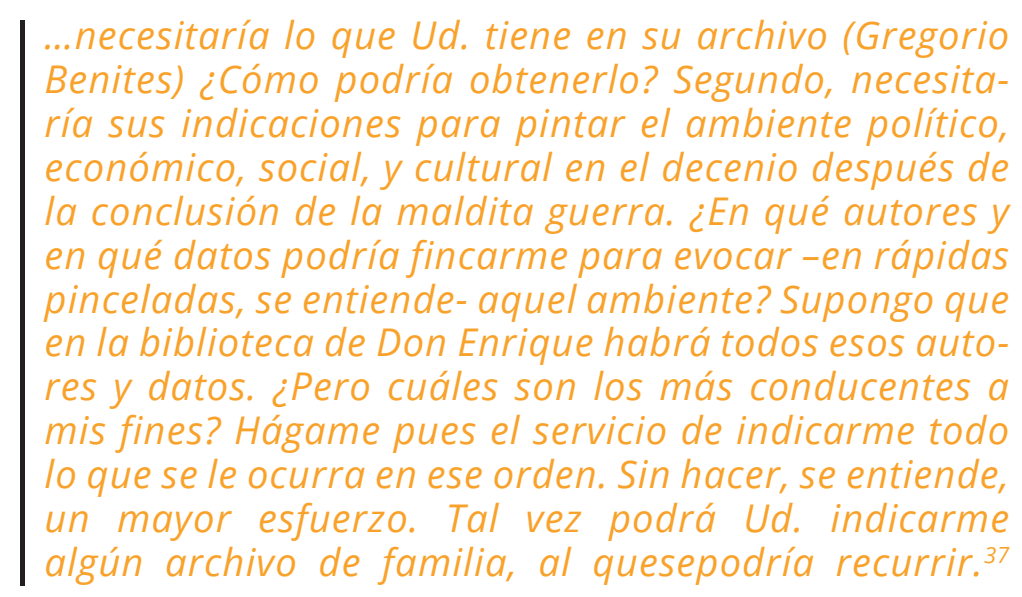

No bstante, la escritura Ayala le comunica en el mes de la obra histórica queda rele- de abril de 1926 y para el cual gada ante un plan de mayor debe proceder a confeccionar urgencia y magnitud: la creación un proyecto que se discutirá de un Banco Central del Para- en el Congreso en el mes de guay, que el mismo presidente junio. ${ }^{38}$ Con ocasión de estos

37 Ibidem. De Rodolfo Ritter a Juan E. O'Leary, Asunción, 21 de marzo de 1926.

38 Ibidem. De Rodolfo Ritter a Juan E. O'Leary, Asunción, 3 de abril de 1926. Es interesante mencionar las observaciones que hace Ritter sobre el proceso de creación del Banco Central: “Esto es necesario en vista de la próxima presentación de un proyecto de reforma monetaria y del establecimiento de un Banco Central. Aquí empieza el drama. El Banco Central tiene que fundarse: B. está en eso de acuerdo con E. Además, a eso obliga al Gobierno un compromiso con el Banco de Inglaterra, 
preparativos se plasma en las cartas, una vez más, Ia familiaridad y el trato diario con el presidente, a quien Ritter define, en estos días, como "una gran alma". A mediados del mes de abril, superponiendo el estudio sobre la creación del Banco Central, el Ministerio de Hacienda le hace un nuevo encargo: la resolución del complejo asunto del Ferrocarril Central del Paraguay. “iProblema magnífico!", como lo define Ritter. ${ }^{39}$

Junto a estas proyecciones mayores, las cartas dan cuenta de complicaciones imprevistas y absorbentes en el plano socioeconómico que Ritter debe atender, como por ejemplo el de las azucareras, que presentaron un largo memorial en que "piden protección aduanera" y la presentación del comercio de Encarnación "alegando que toda la zona del Alto Paraná se mueve bajo la acción del régimen especial establecido para ella". La investigación y resolución de estos trabajos que, en palabras de Ritter, tiene "sobre el yunque" se ven interrumpidos ante la urgencia de la preparación de una ley sobre petróleo que estableciera que los todos los yacimientos de aceites minerales se reservaban para la Nación, que la explotación de aquellos no podrá hacerse sino por un contrato de arriendo con un plazo no mayor de 10 años y que los arrendatarios no podrán ser sino ciudadanos paraguayos o sociedades anónimas paraguayas. ${ }^{40}$

que forma una especie de liga con todos los bancos centrales con moneda sana. Ahí hay unas importantes ventajas a sacar para el Paraguay... Pero lo quisiera o no, el Banco se hará. Así es que, salvando mi responsabilidad, colaboré del modo más activo en la preparación del Proyecto. Eliminé en el mío todo, absolutamente todo, lo que pueda constituir un peligro para el Banco; pero con eso el Banco pierde todo el atractivo, que las atribuciones anteriores ejercían sobre el Sr. Todo el mundo... B. aceptó mis ideas y principios. ¿Los aceptará E.? ¿Aceptaránlas los "honorables"? Soy un sonso: ¿qué me importan al fin las cosas? Sin embargo, tiemblo, me quebranto, por la suerte de ese engendro... Tengo la sensación, rayana en la certidumbre de que, aunque aceptado mi proyecto, el Banco será, con el tiempo no lejano, un desastre: una verdadera desgracia para el país".

39 Ibidem. De Rodolfo Ritter a Juan E. O'Leary, Asunción, 17 de abril de 1926.

40 Ibidem. De Rodolfo Ritter a Juan O'Leary, Asunción, 24 de abril, 1 de mayo y 8 de mayo de 1926. 
Para el mes de julio de 1926 Ritter concluye el informe sobre la cuestión del ferrocarril, anoticia sobre la investigación in situ de la problemática azucarera mediante una visita al ingenio de Tebicuarí, concluye la redacción del proyecto de fundación del Banco de Estado, de la reforma monetaria y de

la casa de la moneda. ${ }^{41}$ Las cartas muestran que, en cuanto portador de un saber especializado, Ritter se sitúa durante el gobierno de Eligio Ayala en un espacio intermedio en la sociedad paraguaya, entre su ciudadanía y sus dirigentes, con la clara capacidad de incidir en las políticas públicas.

\section{Ritter como coordinador editorial de Juan E. O'Leary}

En paralelo a sus labores de asesoramiento, Ritter dedica todo el año 1926 a pergeñar una estrategia para la venta y difusión de las publicaciones producidas por O'Leary en Madrid, actividad que se constituye en un verdadero trasiego. Para poder explicarlo conviene tener en cuenta que la designación de O'Leary como Encargado de Negocios en España tiene como telón de fondo el agravamiento de la controversia con Bolivia por el dominio del Chaco Boreal. El gobierno de Eligio Ayala impuso un programa de gastos milita- res para poner al Paraguay en pie de guerra, de modo que se le instruyó al representante diplomático a que gestionase, ante el gobierno español, la adquisición de armamentos y elementos militares. ${ }^{42}$ Las relaciones diplomáticas entre los dos Estados habían sido establecidas en 1880 luego de la firma del tratado de paz y amistad por el que España reconoció la independencia del Paraguay ${ }^{43}$, pero hasta el nombramiento de O'Leary no le había resultado posible al gobierno paraguayo acreditar una misión diplomá-

41 Ibidem. De Rodolfo Ritter a Juan E. O'Leary, Asunción, 3 de julio de 1926.

42 El sostenido intercambio epistolar permite reconstruir, en parte, la marcha de esas diligencias, así como las controversias que desencadenaron en la opinión política en Paraguay. Véase, por ejemplo, las cartas de Rodolfo Ritter a Juan O'Leary, Asunción, 12 de febrero y 18 de abril de 1929. También Brezzo -Reali (2017).

43 Véase Brezzo (2012). 
tica permanente, limitando la representación a ministros concurrentes: Benjamín Aceval (1889-90), Eusebio Machaín (1895-1910), Cecilio Báez (19181920), Héctor Velázquez (1920) y José P. Montero (1920-1922). ${ }^{44}$

En el contexto de sus actividades diplomáticas O'Leary des- envolvió proyectos editoriales. El primero consistió en la publicación de la segunda edición del libro El Mariscal Solano López que vio la luz de la imprenta en los últimos meses de 1925 con el sello madrileño Félix Moliner. En carta del 31 de octubre Ritter confirma la novedad:

\section{Su noticia de que Ud. acometió ya la impresión de la 2da. edición de su "Mcal. López", me llena de contento iMuy bien! Y se entiende que acepto todos sus planes relativos a mi papel de distribuidor de la obra, así como se entiende que queda en pie la oferta que le hice sobre la financiación de la edición. ${ }^{45}$}

Desde ese momento Rit- plasman en las cartas en una ter asume funciones propias sofisticada estrategia de prode un coordinador editorial paganda y comercialización en tanto nexo entre el autor que despliega con ansiedad y los distribuidores y libreros y minuciosidad a partir de la en el Paraguay. Esas tareas se carta del 15 de mayo de 1926:

\footnotetext{
Ud. dé instrucciones concretas, claras y precisas que no se presten a varias interpretaciones. Su pedido, relativo a circulares para la campaña, lo cumpliré. Pero eso no basta: ¿quién tiene que hacer la distribución de las circulares? ¿A quiénes tienen que dirigirse? Yo, por
}

44 En todos los casos los ministros concurrentes eran los jefes de misiones diplomáticas acreditadas en Reino Unido, Francia, Italia y España.

45 BNP - CJO. De Rodolfo Ritter a Juan O'Leary, Asunción, 31 de octubre de 1925. 
mi parte, no tengo ningunos elementos de juicio para eso. Además: ¿dónde estará el depósito general de los libros? ¿Quién estará encargado de él? Al fin, hay una cantidad de problemas prácticos que resolver. Para el depósito, la distribución (al por mayor) y lo correspondiente a la contabilidad, se precisas comodidades materiales: local, peón, acondicionamiento, etc., etc. Eso no las puede tener sino una casa de comercio. Creo pues que del depósito y de la distribución al por mayor del libro tiene que ser encargada una casa de comercio de toda confianza. Para ese servicio hay que pagar una comisión extra: unos 10 pesos por libro, o tal vez menos. Si Ud. encarga de todas esas funciones a un particular, correrá un sinnúmero de riesgos. ${ }^{46}$

Atendiendo a estas ges- cha de una serie de acciones tiones aconseja a O'Leary que muy meditadas, orientadas a la no se apresure con la venta propaganda y a la distribución: del libro y que, en todo caso, se encarga de recibir "Ios 43 aguarde regresar al Paraguay paquetes" del libro que le llegan para hacer frente a todas estas desde Madrid, los lleva a su casa, contingencias: "tenga siempre donde quedan en su comedor presente la ley general de todas "a modo de depósito", en tanto las actividades en el Paraguay: organiza el reparto entre los el vaí-vaí de todas ellas...". No libreros. Las cuestiones relativas obstante, las cartas que siguen a la venta demandan, a su juicio, dan cuenta de la puesta en mar- de una estrategia comercial:

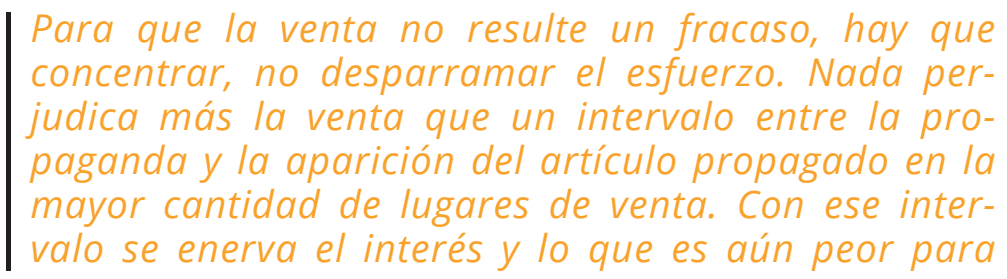

46 Ibidem. De Rodolfo Ritter a Juan E. O'Leary, Asunción, 15 de mayo de 1926. 
un libro, la gente que se interesa por él, empieza a
buscarlo prestado. Así es que la propaganda tiene
que ir simultánea con la venta y el que dirige la venta
tiene que dirigir también la propaganda. Aquí, como
en tantos órdenes de la vida, se impone el comando
único. En síntesis: ya que Ud. me encarga de la parte
más importante de la operación, tiene que encar-
garme también de la dirección de la propaganda. ${ }^{47}$

De modo que la circulación al menos de 500 ejemplares y del libro no se podía anunciar, debía estar precedida de una a su juicio, antes de disponer propaganda de alto impacto:

\begin{abstract}
A más del anuncio con los retratos de Ud. y de López, pegado en todas las esquinas, mandaré imprimir 20, 25, 30 mil volantes. Hablé con Puigbonet, quien está conforme con vender su libro en la campaña donde tiene la organización adecuada. Pero exige para la campaña \$ 5 c/l. más: lo que es justo, por los gastos que implica el envío y la distribución en la campaña. Así es que, considerando racional e imprescindible ese aumento, lo concedí, aunque si tener su autorización: el libro se venderá pues a \$60 en Asunción y a \$ 65 en el resto del país. El precio neto para los libreros será \$50.48
\end{abstract}

La venta inició el 22 de del Paraguay, se acordaba la junio de 1926 y durante la pri- distribución en Buenos Aires, mera semana se vendieron 157 Rio de Janeiro y Montevideo. ${ }^{49}$ ejemplares; según los cálculos de Ritter la edición se agota-

Ahora bien, la circulación ría en poco tiempo si, además del libro de O'Leary queda anu-

47 Ibidem. De Rodolfo Ritter a Juan E. O'Leary, Asunción, 29 de mayo de 1926.

48 Ibidem.

49 Ibidem. De Rodolfo Ritter a Juan E. O'Leary. Asunción, 3 de julio de 1926. 
dada, en el epistolario, al tratamiento de una cuestión sensible en una amistad de tantos años: Ia rehabilitación "oficial" de Francisco Solano López que irrumpe en la agenda política de 1926. En efecto, en los primeros meses de ese año, poco antes de que se cumpliese el centenario del nacimiento de Solano López, un grupo de intelectuales paraguayos, afiliados unos al partido Colorado y otros al partido Liberal, como Juan Stefanich, Carlos Centurión, Anselmo Jover Peralta, Eliseo Da Rosa, Facundo Recalde y Justo Prieto, entre otros, constituyeron un comité de homenaje y designaron a O'Leary como el presidente de honor. El senador por el partido Liberal, Pablo Max Ynsfrán, fue el encargado de presentar en el Congreso Nacional un proyecto para dejar sin efecto la legislación que había puesto a López fuera de la ley en 1869. Desde los inicios de los debates y de los embates en esa dirección, las cartas de Ritter se cubren de argumentos con el propósito de lograr que O'Leary intercediese para la postergación de las acciones oficiales de rehabilitación que podrían interferir y complicar, a su juicio, la agenda diplomática vinculada al conflicto chaqueño. El economista hace la siguiente lectura de esa coyuntura:

Sería la cosa más inoportuna y desastrosa. Como Ud. sabe, el Gobierno está empeñado en una activa "ofensiva diplomática" frente a Bolivia: único camino racional. El Paraguay necesita pues la buena voluntad de los enemigos de ayer. Todo lo que pueda disminuir esa buena voluntad va en detrimento del país. Y es evidente que una ruidosa agitación en torno a la "cuestión histórica" no será hecha para fomentar la buena voluntad de los argentinos. Creo pues que Ud. haría obra de verdadero patriota y de estadista de verdad si, apoyándose en el prestigio en el prestigio que da a Ud. el hecho de ser el iniciador de la reivindicación nacional, aconseja y suplica a los jóvenes futuros diputados colorados de postergar, en nombre de la patria, la rehabilitación de López a una época más oportuna. ${ }^{50}$

50 Ibidem. De Rodolfo Ritter a Juan E. O'Leary. Asunción, 15 de enero de 1926. También véase la carta de 13 de marzo de 1926. 
Si bien, entendía, el desagravio oficial hacia López era "justo y racional" resultaba completamente "criminal" hacerlo primar sobre el presente y el porvenir; por otro lado, le aseguraba a O'Leary que conocía, de primera mano, que el presidente Eligio Ayala y sus ministros bloquearían todo intento de revisión de la historia en esos momentos. De hecho, el proyecto de rehabilitación finalmente no fue tratado en el Congreso. ${ }^{51}$

Además de las funciones relativas a la comercialización del libro, Ritter se ocupa de reproducir en esos meses, en distintas hojas asuncenas, los artículos periodísticos que O'Leary daba a conocer en la prensa madrileña. Por ejemplo, en carta del 22 de mayo de 1926, le anuncia el envío "en paquete separado, de diez números de El Diario con su artículo sobre la radiotelefonía en España". Figuran también comentarios y elogios a las poesías escritas y publicadas por O'Leary, como Nostálgica y el soneto Otoño Madrileño, que se reproducen en hojas asuncenas en febrero de 1926, Toledo, en abril de 1926, y El Escorial. ${ }^{52}$

Al compás de estas tareas, Ritter aconseja a O'Leary con machaconería que salga de la capital española, recorra el interior y haga todo lo posible para visitar Europa: ¿¿Es posible que Ud. piense de veras seguir su estadía de continuo en Madrid? Eso estará muy bien si Ud. se condena a la inmovilidad en la capital gallega y para luchar con el hastío. Pero para bien de Ud. deseo que vea mundo, especialmente París e Italia. La vida en los dos países, según todos los testimonios, es barata". ${ }^{53}$

51 Sobre los debates y el clima que suscitó el proyecto de rehabilitación de Francisco Solano López puede verse Brezzo (2014).

52 BNP -CJO. De Rodolfo Ritter a Juan O'Leary, Asunción, 2 de febrero, 6 de febrero, 3 de abril y 22 de mayo de 1926.

53 Ibidem. De Rodolfo Ritter a Juan O'Leary, Asunción, 31 de octubre de 1925. En carta del 6 de febrero de 1926 insiste: “Y ya que estoy en tren de darle consejos, me permito darle otro: procure conocer la España verdadera, la España escondida detrás de los oropeles prestados de la civilización europea. Ella está en las aldeas y pueblos de las dos Castillas, en las sierras, en los valles de éstas, como la [ilegible]. Creo que Ud. debe hacer lo imposible para visitarlas. ¿Por qué no combina Ud. algo con Blanco Fombona para la primavera o la semana santa? ¿Unas 
Siguiendo estos argumentos,

que tiene el amigo ruso en las O'Leary viaja a París y visita actividades intelectuales del hisalgunas ciudades de España; circunstancia que devela el influjo

toriador paraguayo en su viaje iniciático al Viejo Continente.

\section{Ritter, Eligio Ayala, José P. Guggiari}

Si bien parece que las tareas de Ritter como asesor en el Ministerio de Hacienda finalizan con el inicio de la gestión presidencial de José P. Guggiari, las cartas del año 1928 recuperan algunas decisiones de cara al conflicto chaqueño que lo sitúan como un experto que contribuye a cincelarlas. ${ }^{54}$
La posibilidad de la guerra se vuelve un asunto medular en las cartas con la inauguración del mandato presidencial de José P. Guggiari. En este contexto, desde meses antes de su asunción, Ritter pergeña la que califica como una verdadera "ofensiva diplomática", consistente en un recorrido

excursiones en auto? Con eso Ud. penetrará más al corazón de España que con años de permanencia en Madrid... ¡Qué interesante libro podrá Ud. entonces escribir sobre España! ¡Pero basta de consejos y sugestiones!".

54 Hay que dejar apuntado, sin embargo, que el especial protagonismo que adquiere el conflicto chaqueño irrumpe tempranamente en el epistolario. Ya en la carta del 18 de agosto de 1924 Ritter le refiere a O'Leary con todo detalle los homenajes a los principales referentes intelectuales que se encorvaban en esos años en los archivos para investigar, estudiar y escribir sobre los derechos paraguayos ante las pretensiones bolivianas, a la vez que desliza una crítica por el desbalance público que, a su entender, se hace sobre los méritos de cada uno: “Con el propósito de rendir un homenaje a Domínguez -defensor de los derechos nacionales- se fundó un comité, una liga patriótica ¡Muy bien! Pero no sé por qué desviación, con qué fines ocultos (¿políticos?), todo el honor de la defensa se atribuye a Domínguez solo. A Gondra, La Razón lo trata de traidor y a Moreno como no existente. ¡Es una iniquidad que indigna! Sobre todo, que se sienten aquí motivos inconfesables. En mi indignación, y para poner las cosas en su lugar, digo y repito a todo el mundo que, si Domínguez ciertamente tiene méritos innegables, el verdadero, el genuino defensor de los derechos del Paraguay es Moreno, quien sacrificó dos decenios de su vida a la cuestión y sacó del archivo la mayor parte de los datos con los que se luce hoy Domínguez. Ahí están los tres tomos de su investigación. Y el cuarto acabo de publicarse. Las ideas marchan. Y tal vez una parte de la gente entenderá la verdad". 
del presidente paraguayo por los países limítrofes; se autocalifica como el artífice de ese viaje dirigido a obtener, en sus palabras, "declaraciones netas y categóricas sobre la intangibilidad del Paraguay" de los gobiernos de Brasil y de Argentina, de modo de hacer comprender a Bolivia que los "ensueños de engrandecimiento" propio no los podía realizar a expensas del Paraguay. Los resultados no pueden ser más halagueños, según su perspectiva:

\section{La parte exterior, espectacular, del viaje, en la que se prodigó tantas muestras de simpatía y admira- ción para el Paraguay, Ud. la habrá conocido por los diarios. Lo que más me interesa es [roto] rendi- miento positivo de la "ofensiva diplomática", de la cual - ientre nosotros! - soy el padre espiritual (le ruego ver en esta afirmación no una jactancia o satisfacción de amor propio, sino una constatación de hecho). Pues bien, esa "ofensiva", tomada en el momento psicoló- gico, dio todo el resultado que esperaba y aún mucho más. En síntesis: se obtuvo declaraciones netas y categóricas sobre la intangibilidad del Paraguay. Los ensueños de Bolivia sobre su engrandecimiento a expensas del Paraguay, esfumados. Y eso lo sien- ten y comprenden desde luego los del Altiplano... ${ }^{55}$}

La euforia que proyecta marcaría fecha en la historia este párrafo atraviesa toda la del Paraguay y del Continente?" escritura de la carta dedicada a describir el "éxito completo de la ofensiva diplomática", que obligaría a los bolivianos a "poner la barba en remojo ¿No tuve razón al afirmar [que] ese viaje sería el acto más importante del gobierno de José P., a la vez que

Por otra parte, el cambio de gobierno no significa, para Ritter, que Eligio Ayala deba perder el destaque en la política doméstica a pesar de cierta oposición, dentro del partido Liberal, para que el "hombre de las siete llaves" vaya al Ministerio

55 Ibidem. De Rodolfo Ritter a Juan E. O'Leary. Asunción, 15 de agosto de 1928 
de Hacienda. Ritter es escuchado, vistas que refiere a O'Leary con sus opiniones son acogidas por todo detalle. En el transcurso el presidente electo y por el del encuentro con Guggiari presidente saliente, con quienes le habría manifestado que: mantiene dos extensas entre-

Habiendo metido la mano en la masa y conociendo las cosas, tengo la certidumbre de que será un verdadero desastre para el país y todo el futuro gobierno, si las finanzas caen en otras manos que las de Eligio Ayala: único (único en lo más absoluto del término) capaz de desempeñar la cartera en los momentos actuales. Con esa certidumbre e incapaz de otros motivos que los intereses generales, [...] resolverme a callar: ayer hice una visita a José $P . y$, en una corta pero intensa entrevista, le dije toda mi convicción y mis temores. [roto] su aire pensativo y el cambio de expresión de su rostro, siento que ha [roto] dado en lo más doloroso del problema... ¿Qué decidirá? En unos días lo sabremos. A mis argumentos no contestó sino una sola cosa: "pienso como Ud.", pero pronunciado muy lentamente, con indecisión. ¡Pobre JoséP.! ¿Comprenderá que el destino futuro de su Gobierno se determinará por esa elección?56

\section{Y de la entrevista con Eligio Ayala destaca que:}

Charlamos tres horas. Me contó una cantidad de cosas interesantes, que jamás había sospechado [...]Me ofreció hacer con él, después del 15 de agosto, una gran revista económica. Acepté con gusto. Pero dudo de que el pensamiento y el deseo se transformen en realidad. ${ }^{57}$

Ambas cartas develan el guayos, en los que era recibido lugar que Ritter había alcanzado y cuya palabra era escuchada. en los círculos políticos para-
56 Ibidem.
57 Ibidem. 


\section{Conclusiones}

Como hemos dicho ante- social. Su actuación como asesor riormente, reconstruir el flujo técnico contribuye a calibrar la epistolar entre Ritter y O'Leary importancia y la extensión de su resulta una tarea pendiente $y$, influjo en las políticas públicas por esta razón, este artículo no es del gobierno de Eligio Ayala. A definitivo en cuanto a este tema. un tiempo público y privado, Sin embargo, las piezas epis- el estudio en profundidad de tolares que se han presentado nos permiten echar un somero vistazo a las ideas y percepciones del intelectual ruso que vivió en el Paraguay durante más de cuarenta años y que se comprometió con su vida política y este epistolario nos invita a tomar conciencia del valor de la cultura epistolar para conocer a figuras prominentes de la política y de la vida intelectual paraguaya en el siglo veinte, así como a sus redes de influencia. 


\section{Referencias bibliográficas}

Alberdi, J.B. y Benites, G. 2006-2007. Epistolario inédito (1864- 1883). Asunción: Academia Paraguaya de la Historia - Fundación Biblioteca y Archivo de Jorge M. Furt - Universidad Nacional de General San Martín, 3 tomos.

Alexandróva, M. 2017. “Los rusos, héroes de Paraguay”, Revista Digital Russia Beyond, 25 de enero.

Brezzo, L.M. y Reali, M.L. 2017. Combatir con la pluma en la mano. Dos intelectuales en la Guerra del Chaco: Juan O'Leary y Luis Alberto de Herrera, Asunción, Servilibro.

Brezzo, L.M. 2012. "Vivimos en tiempos de las más grandes reivindicaciones. Las cartas privadas entre dos letrados paraguayos durante la primera década del siglo XX: Gregorio Benites y Juan E. O Leary", Revista Paraguaya de Sociología, n²141, pp.193-233.

Careaga, X. 2007. Ritter. Asunción, edición del autor.

Brezzo, L.M. 2014. El historiador y el general: imposiciones y disensos en torno torno a la interpretación pública de la historia en Paraguay, Nuevo Mundo Mundos Nuevos [Online]. URL: http://journals.openedition.org/nuevomundo/67479

Giovini Gramatchicoff, L.E.2009. Aporte de los inmigrantes rusos al desarrollo del Paraguay. Asunción, Ministerio de Relaciones Exteriores.

Lewis, P. 2016. Partidos políticos y generaciones en Paraguay 1869 - 1940. Asunción, Tiempo de Historia.

Myers, J. 2014-2015. “El epistolario como conversación humanista: la correspondencia intelectual de Alfonso Reyes y Genaro Estrada (1916-1939)", Políticas de la Memoria, Buenos Aires, CEDINCI, n 15, pp. 53-70.

Nakayama, E. 2017. La inmigración rusa al Paraguay, Asunción, s/e.

Quinteros, M.C. y Suárez Morales, C.D. 2016. “Estrategias de lucha del antiperonismo latinoamericano: Juan Natalicio González y Germán Arciniegas" en Ernesto Bohoslavsky y João Fábio Bertonha, Circule por la derecha: percepciones, redes y contactos entre las derechas sudamericanas, 1917 1973, Los Polvorines, Universidad Nacional de General Sarmiento, pp-189 $-209$.

Reali, M.L. 2012. “Los intercambios epistolares entre Luis A. de Herrera y Juan E. O'Leary en el período de surgimiento y consolidación de un movimiento historiográfico revisionista sobre la Guerra del Paraguay", en Juan Manuel Casal y Thomas Whigham (eds.), Paraguay en la historia, la literatura y la memoria, Asunción, Tiempo de Historia, pp. 391- 411.

Sansón Corbo, T. 2018. “La historiografía liberal y la época de El Semana- 
rio", en Herib Caballero Campos y Carlos Gómez Florentín (editores), Nación y Modernidad en Moldes de Plomo, Asunción, Universidad Nacional de Asunción, p. 41 - 57.

Scavone Yegros. R. 2010. "Guerra internacional y enfrentamientos politicos (1920-1954), en Historia del Paraguay, Asunción, Taurus, pp. 225-263.

Seiferheld, Alfredo. 1984. Los judíos en el Paraguay, Asunción, El Lector.

Tutté, A. 2017. "Juan Natalicio González y la revista cultural Guarania: sociabilidades, intelectuales y proyecto político", Anuario del Centro de Estudios Históricos Prof. Carlos S. A. Segreti, n 16, pp. 157-171.

Tutté, A. 2019. "Una "patriótica empresa": estrategia editorial y proyecto político en Juan Natalicio González (1925-1949), Revista Paraguaya de Historia, $n^{\circ} 2$, pp.49-80.

VV.AA. 2009. Universidad Nacional de Asunción. 120 años de historia, Asunción, UNA.

\section{Fuentes}

Biblioteca Nacional del Paraguay. Colección Juan E. O'Leary. Correspondencia Pública y privada. Años 1916 - 1946. 